\title{
Why Operationism Doesn't Go Away: Extrascientific Incentives of Social-Psychological Research*†
}

\author{
GEORGE C. ROSENWALD, Psychology, University of Michigan
}

Give me where to stand and I shall move the earth. - Archimedes

Theoretical progress, as envisioned within the discipline of social psychology, is slow to arrive (Gergen 1982; Meehl 1978; Scriven 1964). Investigators committed to the experimental method, the method often deemed most powerful of all, account for this by referring to the complexity of the subject matter; others point a finger at the experimentalists' methodological commitment itself (Allport 1961; Giorgi 1970; Harré and Secord 1972). Perhaps both sides are right. In any case, people beset by the large and small perplexities of life rarely turn to academic psychology for answers. Instead, they seek clarification from experts, from the humanities, from admired models and occasionally from the lessons gleaned in their own life histories. It has been suggested that this is so because what people do in laboratories tells us little about what they do elsewhere (Silverman 1977). Further, even our laboratory-derived knowledge exhibits little of the cumulative character we associate with the scientific method (Katz 1967) and without such reliability and continuity in the laboratory there can be no confident generalization beyond it (Meehl 1978).

Despite mounting criticism, laboratory investigations have continued to grow in esteem and occupy more and more of our journal space. At the heart of social-psychological experimentation lies the pursuit of operational definitions. Bridgman's operationalist philosophy could hardly have shaped the course of psychological research more thoroughly or enduringly (Bridgman 1927). Although the premisses on which this philosophy rests have been powerfully challenged by philosophers of science, nothing seems to avail against this anachronism (cf. Hanson 1973; Hempel 1966; Kuhn 1962; Suppe 1977; and many others). One may well wonder why. A main objective of this paper is to explore the incentives

* Received 29.6.84

$\dagger$ I gratefully acknowledge the benefits derived from discussions with Barnaby Barratt, Frithjof Bergmann, Akeel Bilgrami, Melvin Manis, Jack Meiland and Peter Railton. 
of a scientific strategy which delivers a scanty theoretical yield and which lacks firm philosophical supports. The premiss underlying the present discussion is that, whereas operationism can be criticized (or defended) on logical grounds, its persistence in the face of methodological critique and of its disappointing theoretical yield cannot. We must seek answers outside the philosophy of science, for instance, in the sociology of professions and in the explicit and implicit missions which learned disciplines set for themselves (Leahy 1980).

The philosophical critique of operationism has led to a rejection of the notion that theoretically neutral measurement observations can be gradually refined and take their place in a theoretical edifice. Theoretical and operational refinement go hand in hand, and there are no theory-free operations. A host of other difficulties have been recognized as well. But these criticisms have been largely without effect. Perhaps experimenters are not impressed by philosophical rebuttals. My purpose in this paper is neither to add yet another theoretical refutation nor to offer an alternative methodological programme. Methodological innovations can be only partly relevant and will probably not be widely accepted until the larger framework-the incentives and tacit hopes supporting the discipline in its current form-is examined and modified. I shall argue that the discipline of experimental social psychology is ruled by an unacknowledged, historically specific social-psychological imperative and that 'broadening' its methodological approaches in the manner suggested by a host of reformers will not suffice to rescue it from its peculiar predicament.

To make this argument plausible and to point an approximate way out of the predicament, a particular difficulty encountered by operationalist social psychology must be made clear in a manner somewhat neglected in the critical literature. The difficulty concerns the role of pretheoretical knowledge in the progress of social-psychological science. It is important to be clear about this and to see it as something more than a handicap for operationism; it reveals something about the subject matter of social psychology and eventually about the extrascientific incentives guiding the discipline. To accomplish this clarification I rely on the case-study method, drawing on excerpts from one voluminous research literature. Since what stimulates a new study is usually the critical evaluation or reinterpretation of a previous study, attention will focus on these evaluations. I therefore begin with an 'inside view', a study of how adherence to the operationalist principle influences the actual progress of research on a theoretical problem and what specific difficulties it involves. This will lead to an exploration of the extrascientific incentives which sustain operationism in social psychology. Viewing the field in its societal context may be judged helpful if it accounts for the general persistence in a relatively unproductive scientific strategy and if it 
contributes to a more receptive climate for non-operationist approaches. This is, however, a matter of historical processes, and I shall refrain from making specific proposals or predictions.

To comprehend the persistence of operationism, it is well to keep the attractions of the laboratory in mind-especially by contrast with the helter-skelter social world on which experimental findings are intended to shed light. These attractions consist of a constant, standardized stimulus field, the regulated manipulation of selected independent variables, and the simplification and objectification of dependent variables. These conditions are placed in the service of shedding light on certain complex and unruly phenomena occurring in 'real life'. For the findings to be generalizable, the laboratory conditions should be relatively unambiguous empirical realizations of theoretical variables encumbered by minimal situational artifacts. Most experimenters believe that theoretical progress (in any scientific field) depends on the development of relatively robust, all-purpose laboratory operations. It is a common observation, however, that many of these operations in human psychology have been nearly as complex and ambiguous as the original real-life phenomena which they were meant to illuminate. This difficulty is widely recognized in the literature but has not been adequately explored in regard to its limits. Proposed solutions have accordingly seemed utopian and remained largely ignored, for instance, Aronson and Carlsmith's discussion of 'purification' (1968, pp. 15-16) or balanced replications (p. 21).

To put it simply, the concept of generalizability is not adequate to the problem. 'Real life' is the stimulus to research as well as its proving ground. It therefore makes a difference whether we speak of findings generalizing from one laboratory setting to another or to 'real life'. The logical distinctions between reliability and validity or between construct and external validity do not adequately reflect the fact that the previous study stood in the same dual relation to 'real life' (as both its stimulus and proving ground) as the present study which is supposed to improve on it. Finally, the distinction between stimulus and proving ground is itself unsatisfactory because it obliterates the decisive fact that the psychologist represents and exemplifies the inhabitants of the real world'-the object of theory-while he is at the same time the ruler of the laboratory which is supposed to give us a handle on that world-the subject of theory. I call this fact decisive because it sets up a specific tension in the practitioners of the discipline which is rarely discussed except in strictly methodological terms. This too will be taken up in the case study and subsequently discussed as to its broader significance.

For illustrative purposes, I have selected the history of research on forced compliance. This seems to have slowed down sufficiently to permit a retrospective analysis. I do not, however, propose to give a full 
or even systematic survey of the literature. Rather, I have chosen steps in the history of this research which exemplify operationist strategy and which illustrate its implications for the production of theoretical knowledge. I claim only that, in regard to this aim, my summary is not biased. I shall look at parts of it in detail to evaluate how the actual practice of research appears in the light of the classical philosophy of science and what it can tell us about the tension between 'real life' and the laboratory which is peculiar to social psychology. Toward the end of the paper I shall briefly touch on related problems in other social sciences.

\section{ESTIMATING PROGRESS IN SCIENTIFIC PSYCHOLOGY}

I leave for later whether the case of cognitive dissonance $(C D)$ theory and forced compliance research is a fair specimen. As will be recalled, experimental social psychologists have demonstrated that if people are paid to make public statements contrary to their own opinions, they will subsequently come to believe these statements; paradoxically, the less they are paid to tell these lies, the more they believe them. The explanation for this finding is that the person who gets paid a large amount has sufficient external incentive to help him justify his prevarication whereas the person who gets paid little justifies his lies by persuading himself that they are at least partly true. Both must reduce "cognitive dissonance'- the unpleasant inconsistency between belief and avowal-but the latter person is forced to do so by changing his mind, while the former, who 'did it for the money', keeps his original opinion intact.

In Hempel's terms, we can identify the internal principles of the theory as linking the various mental entities (cognitions, feelings) among themselves. The bridging principles theoretically link these mental entities with the stressful belief-avowal inconsistency in the forced compliance situation. The measurement operation consists of the average shift in attitude ratings following the experimental manipulation in the laboratory. If this effect is shown to be consistent, we have framed a law. Of course, it states only an empirical regularity; it is not an explanation in itself. The theory of $C D$ is offered as an explanation of the laboratory effect.

The general cognitive dissonance hypothesis, which has instigated this research, was first put forward by Festinger in 1957. The first and perhaps best known confirmation of it was published by Festinger and Carlsmith in 1959. It as been chronicled that 'Festinger and Carlsmith's confirmation of [the dissonance] prediction has generated more empirical research and theoretical controversy than any other finding in social psychology' (Eagly and Himmelfarb 1978, p. 532), and yet the discouraging verdict after years of intensive research was that 'the distribution of dissonance, neutral, and [contradictory] effects obeys a normal 
curve' (Sears and Abeles, 1969, pp. 265-66). On the one hand, only the most hardbitten sceptic would totally dismiss the hypothesis today. The forced compliance effect has been demonstrated in an astonishing range of settings. By now there is also a great deal of atheoretical and informal know-how relevant to producing it: surveying the experimental literature, Wicklund and Brehm list the subject's personal commitment, the salience of initial attitudes, choice, awareness of the dissonant relations and foreseeability of consequences among the critical requirements for producing any effect in the forced compliance situation (Wicklund and Brehm 1976).

On the other hand, we have only little to show in the way of detailed theoretical knowledge about the cognitive processes said to underlie the effect. We are in fact still far from answering even the most fundamental questions raised by $C D$ theory, for instance, what is meant by saying two cognitions are incompatible with one another, not to mention degrees of incompatibility. Equally little is known about alternative ways in which an incompatibility will be resolved under given circumstances. For instance, Festinger asked which of two given conflicting beliefs, perceptions or memories would be more easily altered in reducing $C D$. Surely, this will depend on how firmly a cognition has come to be held by a person and on how central it is in his or her system of beliefs. So one may wonder what will happen when one central cognition conflicts with several weaker, peripheral ones. We have no clear conception of how the relevant factors interact in the production and resolution of $C D$, nor a comprehensive, higher-level integration of $C D$ theory with theories of perceptual, memory or affective processes, nor with theories of social choice and group formation. Yet these are the concerns on which Festinger's theory touched (1957, pp. 262-66). He also entertained a number of astute typological hypotheses regarding which little evidence has become available (1957, pp. 266-75). The ratio of effort to progress in dealing with these questions has been disappointing (cf. Meehl 1978).

To put it briefly, there is little refinement of the internal principles of $C D$ theory and no significant reduction of $C D$ theory to a more inclusive theory. An unfortunate consequence of this point is that we have learned practically nothing about how to escape $C D$ other than by self-deception or confusion. One might suppose that cognitive contradictions could be rationally resolved. But of this there is no mention in the literature. There are currently signs of a trend to reduce the scope of $C D$ theory, for instance, assigning its application to a certain range only of cognitive incompatibility (Fazio, Zanna and Cooper 1977). I am not the first to cite this research history as casting a shadow on the promise of experimentation in social psychology (e.g., Harré and Secord 1972, pp. 53-54; Gergen 1982, pp. 116-20). 


\section{HYPOCRISY, SELF-DECEPTION AND PERPLEXITY}

And yet the $C D$ hypothesis has not been abandoned and remains as intriguing as ever. I suggest that it appeals widely and persistently because it addresses a common perplexing phenomenon of 'real life'. For instance, you flatter someone you have disliked and subsequently find some redeeming features in his character. (The sour-grapes phenomenon is another, even better known example of this kind of self-deception.) The occasions on which we say what we do not (quite) believe are numerous-for instance, hypocrisy, enthusiasm, guilt and boastfulness. To the extent that such insincere avowals alter our opinion, we are apt to experience a change in our public posture and in our affiliations-though not for good! In time, the grounded beliefs we formerly held are apt to re-emerge, altering our postures and alliances again. Social pressure vying with the inertia of our own parti pris is apt to result in inconstancy and confusion about where we really stand. Not only in others' eyes, but in our own, our authenticity is in jeopardy. Thus, the $C D$ hypothesis may be interesting because it deals with a social-cognitive predicament which we encounter relatively frequently, which is difficult to avoid (largely because of social pressures), which we may recognize as a source of self-deception, but which we are often unable to prevent or reverse. ${ }^{1}$

I further suggest that the hypocrisy/self-deception phenomenon is a typical instance of human perplexity-a psychological state or process which we grasp partly, but not sufficiently, even after much trying, and which we cannot escape. Cognitively, we cannot make the pieces add up to a whole or get control of the predicament. Our insights remain unconnected. Perplexity so defined signals the rudiment of understanding as well as its frustrating curtailment. (What distinguishes perplexity from simple ignorance is this half-seeing and half-knowing.) Perplexity is what we experience when we realize that a poem or an overheard conversation has a meaning but one about which we must remain unclear in our mind.

Perplexity is not merely a state of mind, but a characteristic of the social order. We are often hard put to know what is in our best interest, and how to deal with opportunities and difficulties in various sectors of our lives. Normally we function in society without understanding its dynamics and the part we play in them. Perplexities are therefore not idiosyncratic, but social in nature. They are kept from evolving into clearly formulated problems by a built-in self-preservative factor, and thus block ameliorative action. For instance, we may regard them as inevitable, or we construct them out of widespread irrational beliefs. This muddles objective problems cognitively without any significant reduction in subjective dissatisfaction or suffering.

1 I do not deny that $C D$ also appealed to psychologists because of its role in the history of attitude change research. 
Yet efforts to clarify perplexities into formulated problems commonly encounter resistance from the perplexed individuals (Sennett and Cobb 1973; Earnest 1982). This is consistent with the fact that perplexities are socialized. Among the pillars of individual perplexity are certain kinds of naiveté, apathy, prejudice, platitude, dogma and a variety of stabilizing sentiments and beliefs buttressed by unconscious defences. None of these is independent of social norms. Thus, perplexities maintain the social order while they maintain themselves, all the while fanning a widespread restlessness. The social prevalence of more or less coherent, realistic ideological belief systems indirectly suggests the pressures which contradictions and obscurities in social life put on people's cognitive capacities.

I suggest that the forced compliance phenomenon derives its persistent interest from the fact that it exhibits the formal characteristics of a perplexity -it illustrates how social cohesion may be obtained at the expense of the individual's rationality and self-transparence. Dissonance theory as applied to forced compliance opens up the possibility of achieving intellectual and eventually practical mastery over this troublesome phenomenon. ${ }^{2}$ The theory appears relevant to contemporary individuals in an even more encompassing sense because it deals with the irrational manner in which we often resolve contradictions in our social experience. For instance, if an individual does not enjoy the advantages which his society claims to bestow on him, he must resolve the contradiction and perhaps finds it easiest to do so by deceiving himself. The problem is pervasive as well as pressing. Since selfdeception does not remove its nagging stimulus, the expectation of grasping irrationality conceptually opens up the prospect of resolving societal dilemmas more effectively and satisfactorily. At any rate, it is not easy to account for the enormous interest which forced compliance has been able to mobilize in the learned community if one tries to segregate the history of this research from the life world of the investigators and consumers. In the last section of this paper I shall indicate why the real-life relevancy of this problem is not only an inspiration, but an obstacle to theoretical progress.

\section{OPERATIONALIZATION AND CRITICISM}

To lay the groundwork for such an analysis, we must examine the influence of operationalist strategy on the progress from one study to the next. Our focus will be on the criticisms of particular operations. In an

2 The relevance of $C D$ theory to human suffering has been acknowledged from the outset. It was first formulated to account for certain rumours about imminent catastrophes which were being spread in India shortly after an earthquake had occurred there. Festinger offered the explanation that '.. as a result of the earthquake, these people were already frightened, and the rumors served the function of giving them something to be frightened about' (Festinger 1957, p. vii). 
investigation I have already mentioned, Festinger and Carlsmith hired undergraduate students to convey to 'a waiting subject' that a dull task they had been occupied with for an hour was in fact interesting and to persuade the new 'subject' that she would find it interesting and enjoyable as well. Students who had been paid one dollar to make this communication subsequently showed a more positive evaluation of the dull task than did students who had been paid twenty dollars.

Soon after the study was published, doubts were raised in some quarters as to the operationalization. In particular, it was suggested that twenty dollars was an unrealistically high wage to pay for the little service that was asked. Subjects might construe the situation: '[The task] must have been [dull] if they are paying me so much for [touting it as interesting]' (Brehm and Cohen 1962, p. 74). On the strength of this 'definition of the situation'-so ran the critique--the high-reward subjects would come to think of the task as all the more unpleasant, and this, rather than the alleged $C D$ effect in the low-reward group, accounted for the difference between the groups. In other words, the critics held that because the laboratory operation had an unintended side effect, the theory had not been tested at all.

To set matters right, Cohen carried out an experiment similar to the Festinger and Carlsmith study, but using a larger range of inducements and including smaller values. Yale undergraduates were paid ten dollars, five dollars, one dollar or fifty cents to write an essay favouring the intervention of the police in a recent student riot. Cohen found that subjects who had been paid fifty cents showed greater attitude change in the direction of the advocated opinion than did subjects who had been paid one dollar. This study was intended to dispose of the twenty dollar problem. Cohen concluded that the dissonance hypothesis was confirmed because his study was free from this defect: 'No more suspicion can be attached to a $\$ 1$ offer than to a $50 \notin$ offer', he wrote (Cohen 1962, p. 77).

Although this study supposedly rehabilitated the theory, Rosenberg soon published an article in which he criticized both of the previous studies. He speculated that subjects might have interpreted Cohen's offer of money as a bribe, as an attempt to test whether their fierce anti-police attitudes would remain steadfast or whether they could be bought off. This would engender suspicion and anger. As a result the subjects would demonstrate their autonomy by holding fast to their anti-police attitudes, hoping to frustrate the experimenter at the same time (Rosenberg 1965).

To remedy this fault, Rosenberg carried out a study in which the subjects were led to believe they were participating in two unrelated experiments. Presumably this procedure would eliminate the disturbing artifacts in Cohen's study. The results contradicted the $C D$ hypothesis. 
However, it was not long until Rosenberg's study was in turn dismissed on various grounds (Aronson 1966; Brehm 1965). Carlsmith, Collins and Helmreich (1966) then proposed a new formulation reconciling Festinger and Carlsmith's and Rosenberg's findings. Unfortunately this reconciliation failed to account for other findings. Ad hoc theories were advanced as to the slight variations in procedure which might have caused other replications of Festinger and Carlsmith to fail (Nuttin 1964; Janis and Gilmore 1965).

A further stage in this brief survey of progress in forced compliance research is represented by the investigations of Barry Collins (1969), who speculated on various other kinds of stress a subject might have experienced in the situation contrived by Festinger and Carlsmith. A subject might have feared social retaliation, or his self-esteem might have suffered from having made a fool of himself before 'that attractive female coed', or he might have been distressed lest his misleading statements could cause someone unpleasant consequences. Collins reported more than a dozen experiments in which experimental conditions were further varied. But these new studies made no noteworthy progress toward the perfection of a reliable operation.

Typically, the operations employed in each study were underdetermined, that is, open to alternative interpretations. A subsequent investigation, carried out to decide the issue, was underdetermined in a different way so that the data it furnished did not arbitrate among the alternative interpretations previously offered. Although physics too knows theories which are richer than the available evidence, the two fields differ greatly as regards the theoretical level at which the underdetermination occurs (e.g., the particle theory of light $\mathrm{i} s$. what a particular subject thought about the events taking place on a certain day in a Stanford University laboratory). In the next section of this paper I shall show that pretheoretical knowledge plays a distinctive role in maintaining this underdetermination especially in regard to the humanly most perplexing and therefore most interesting phenomena.

\section{THE LOGIC OF CRITICISM}

It is a commonplace that science thrives on criticism. Yet given the unsatisfactory progress of experimental human psychology, it is worth examining the logic of the criticisms we have sampled.

\section{(l) Positive Findings}

The most important point to be noted is that the original 'twenty dollars criticism' and most of the other critical analyses, whether supportive or sceptical of $C D$ theory, were not stimulated by failed predictions. Festinger and Carlsmith observed the events they had forecast. But instead of being accepted as corroborative, the events were discounted on the 
assumption that other events would have been observed if it had not been for situational artifacts. This assumption was based on commonsense considerations, on an understanding-of-social-situations rather than on established scientific knowledge concerning the credibility of financial rewards. Thus, pretheoretical knowledge prevailed over hypothetico-deductive logic. ${ }^{3}$

Imaginative, intuitive and even irrational factors may play a role not only in the context of discovery, as has always been conceded, but in the context of justification as well (Reichenbach 1938). 'Statements about events' are not always decisive in the latter (Popper 1958, pp. 88ff.). It may be countered that the critiques of Rosenberg and others were actually attempts at alternative explanation and that we are therefore moving into new contexts of discovery. I shall take this point up shortly.

\section{(2) Untested Assumptions}

The insights on which these critiques rest are not derived from scientific investigations; rather they are in need of testing. In this sense, they are subjective. But subjective is not idiosyncratic. We may surmise that overpaying someone will make him suspicious. We do not know it in any systematic way (yet). But it seems plausible to anyone experienced in human affairs, and plausibility is sufficient to undermine our faith in certain laboratory findings. McGuire (1976) and Gergen (1982) recognize this point fully. Cook and Campbell (1979) acknowledge it as well, though without its full implications, in their distinction between 'internal' and 'construct' validity.

Pretheoretical assumptions complicate the evaluation of findings in other sciences as well. They constitute a 'supporting chorus of background beliefs' (Quine and Ullian 1970, p. 68). For this reason, it is held by many that crucial experiments cannot be carried out, that a corroborated hypothesis has merely withstood a challenge, and that a falsified one need not be discarded (Greenwald 1975; Greenwald and Ronis 1981). What distinguishes social psychology from other sciences is that the 'background beliefs' are largely grounded in the critic's everyday experience with 'real life' outside the laboratory. Human beings, who are subjects and objects of inquiry-the knowers and the to-be-knowntalk back to the investigator about how they are being studied: 'As one of your subjects I would have experienced such-and-so!' The massive acquaintance with life on which critics base their challenges of laboratory studies commonly command the assent of others to an extent which the objective findings themselves cannot always muster. The experi-

3 I believe this is the reason why studies in human psychology (and in other human sciences) are often judged harshly by outside critics even when they are logically immaculate. 
mental physical scientist need not contend with a comparable stock of competing 'real-life' knowledge.

\section{(3) Subjective Processing}

Let us be clearer about this 'real-life' knowledge. Rosenberg brought a wealth of knowledge to bear on the situation-knowledge about the appropriateness of monetary rewards for various services; knowledge about the interpretations people place on being 'overpaid', on being offered bribes, on being betrayed by peers; knowledge about the suspicion in which people hold psychological experiments; and knowledge about how all (and more) of these elements may be combined. This knowledge does not pertain to the $C D$ hypothesis, but to the features making up experimental situations qua social encounters. Not only is this knowledge, acquired in a lifetime, nearly beyond articulation, but it was summoned and 'computed' according to rules about which cognitive psychology tells us very little. What knowledge would be relevant to the understanding of this situation was spontaneously 'decided' by Rosenberg and each of the other critics. There are no guidelines or known programmes for the empathic re-enactment of another's experience, and it is rarely appreciated by experimentalists just how vast is the domain of informal knowledge on which they depend and which may be challenged.

Thus, the knowledge which enters into the formulation of these criticisms is subjective, first, in a negative sense: It lacks any theoretical basis; it is 'in need of testing'. Second, it is subjective in a positive sense, namely as originating and being processed in the implicit ways just described. It may be countered that hypotheses are often invented in this way. But, as I shall shortly argue, the interpretations which Rosenberg and other investigators proposed are not 'alternative hypotheses' in the usual sense.

By subjective we do not mean private or arbitrary (Natsoulas 1978). We are free to collect further evidence and to decide whether we accept Rosenberg's interpretation. In fact, his interpretation is today considered, along with Festinger and Carlsmith's findings, a significant milestone in the history of $C D$ research, its 'subjective' status notwithstanding.

If we wish to pursue the sources of Rosenberg's insight further, we may dig into his own psychology by means of life-historical case study and/or into the protocol of Cohen's study for clues to the impression of bribery his procedure allegedly conveyed to his subjects. Subjective insights are not conversation stoppers. On the contrary, the pursuit of these insights to their sources may shed light on the way 'real life' invades the laboratory. 


\section{(4) Alternative Hypotheses?}

Perhaps the criticisms we have reviewed are simply alternative explanations of empirical findings such as occur in all sciences. If so, then Rosenberg was testing a rival hypothesis. But this is not so! As a rule, critics analyzing previous forced compliance experiments usually offered alternative (conceptual) interpretations of the earlier findings, for instance, by pointing out an operational flaw. But instead of collecting direct evidence in support of these interpretations, they carried out new experiments testing the same hypothesis but free of the particular blemish they had cited. In other words, the critic reported a plausibly improved design. For this reason, it was rarely possible to draw inferences from a later, 'improved' design concerning the alleged defectiveness of a previous design, and our skill in producing $C D$ effects is accordingly only marginally more dependable today than it was at first.

This is not astonishing. It takes only a moment's reflection to realize that tests of hypotheses about operations are as open to interpretation as hypotheses about $C D$. The most satisfactory evidence concerning what Cohen's subjects felt and thought about the experimental set-up might be obtained from interviews. Rosenberg rejected this method as 'open to the very kind of contamination it seeks to disclose' (Rosenberg 1965, p. 30). Yet Rosenberg's hypothesis was clearly a historical one; it concerned the particular undergraduates in Cohen's laboratory. Testing such a hypothesis in a manner convincing to operationalists is a formidable and therefore largely untried challenge.

The retroduction model described by Hanson does not fit these cases either (Hanson 1971). Usually revised hypotheses are retroduced after events have been observed which are anomalous with respect to an original forecast. We have already seen that this was not the case in several of the studies cited. On the contrary, the events were in accord with the hypotheses but anomalous with respect to pretheoretical knowledge.

\section{(5) Technical Wisdom}

Neopositivists have argued against Bridgman that theoretical and operational progress are reciprocal. What our case study suggests is that operations are at times refined at the behest of informal, subjective knowledge, but that this refinement has failed to bring any remarkable theoretical pay-off. This has ambiguous consequences for the growth of knowledge. On the one hand, workers in the field of $C D$ research have gathered informal technical wisdom regarding various experimental procedures. This wisdom remains implicit, however:

Although investigators who have had experience working with the theory seem to have little difficulty intuiting its boundary conditions, they have had consider- 
able difficulty communicating this to other people; indeed, a situation has evolved which can best be described by the statement: "if you want to be sure, ask Leon'. [Aronson 1969, p. 5.]

On the other hand, the algorithm of cognitive dynamics-the mutability of various kinds of cognitive elements; the profundity, extensiveness and persistence of their changes; the resistance of elements to change; or the sources of this resistance-have not been substantially articulated.

Those who take a holistic view of scientific knowledge as an interrelated system of propositions without immune sectors may recommend tolerance and deny a categorical distinction between 'foreground' and 'background' assumptions (Quine 1961). But this does not alter the fact that the central questions which launched this research programme and which remain largely unanswered were concerned with the dynamics of cognition, and not with the sorts of variables which have inadvertently arisen in the evaluation of experimental designs.

The accumulation of technical knowledge is not an idle pursuit, of course. Every advanced science requires it. For instance,

An experiment in physics is the precise observation of phenomena accompanied by an interpretation of these phenomena; this interpretation substitutes for the concrete data really gathered by observation abstract and symbolic representations which correspond to them by virtue of the theories admitted by the observer. [Duhem 1962, p. 147; second italics added.]

Our case differs in three respects: (a) No operational theory exists, and the accumulated studies have not resulted in one. Therefore, experimental social psychology, unlike physics, has very few 'stubborn facts' (Cook and Campbell 1979, pp. 24-25). This is partly so because (b) the technical wisdom accumulated is not directly relevant to $C D$ or forced compliance as such, but to plausible deceptions of many kinds which occur only rarely in any specific theoretical context. For instance: Whenever an experimenter promises a reward to a subject, he must beware of appearing to offer a bribe! (c) As already mentioned, the technical wisdom remains of uncertain generality because it is rarely tested directly.

Despite these reservations, the pursuit of an adequate operation has been the life force behind this research history and has given shape to the acquired knowledge. That is why, despite the seeming futility of the search, experimental progress depends on it. While pretheoretical knowledge plays a most conspicuous role in the criticism of previous studies, it is just as indispensable to the construction of new ones. This is especially true when novel concepts are introduced, as by Festinger, which require the invention of novel operations rather than recourse to tried-and-true ones (e.g., IQ, Taylor Manifest Anxiety Scale). These will be especially vulnerable to reinterpretation. Gergen regards pretheoret- 
ical knowledge as very powerful when he asserts that psychologists obtain support for hypotheses because they are familiar with their culture and can not only guess correctly how, when and where to gather evidence for a hypothesis, but that they could equally well find evidence for its negation (Gergen 1982).

\section{(6) Limits of Subjectivity}

We have seen that the abundance of pretheoretical knowledge is a blessing and an embarrassment for social psychology. While it seems an inexhaustible resource in the design of effective experiments as well as in the framing of equally effective criticisms of experiments, it is in fact a budgeted resource. Each study is followed by another, and each criticism is superseded by a new one. But eventually the chain stops. For the time being, one investigator has the last word-not because his findings are the last word but because no one seems able to think of a reinterpretation of his design and because his findings have reached an acceptable degree of reliability. These termination criteria are at best conventional, at worst arbitrary. In short, subjectivity governs not only the mobilization of pretheoretical knowledge but its resignation, and this translates directly into theoretical coarseness.

To summarize these six points, our review of forced compliance research shows that, in addition to scientifically warranted generalizations, experimental psychologists rely on an extensive unsystematized body of non-scientific knowledge of a kind and magnitude not encountered in the physical sciences when designing and criticizing experimental operations. Guided by this knowledge, they are at times prepared to set aside confirmatory as well as disconfirmatory laboratory findings. Their reinterpretations of previous experiments may be testable but are in fact rarely tested. Some of these reinterpretations would require non-behavioural and/or historical approaches to testing which contemporary scientific psychology has been unable to master until now. Although many of these untested suppositions have had considerable impact on the course of research, they have not cumulated into a set of operations or an operational theory comparable to, say, the physicist's or physiologist's. To the limited extent they have so cumulated, cognitive theory has not benefited. The wealth of prescientific knowledge demonstrated in these pages remains excluded from the officially admitted findings of the laboratory. Therefore, these are invariably less informative than would be required to raise the level of the untested knowledge which we already have, on which we constantly depend and which is our touchstone when we evaluate laboratory findings. Operationalist psychology draws heavily on the capital of ordinary knowledge-much more than is officially acknowledged-but pays no dividends and does not appreciate substantially. 


\section{IMPLICATIONS FOR HUMAN PSYCHOLOGY}

One can take two perspectives on the problematic role which prescientific knowledge plays in the operationist programme. The common view is to regard the resulting impasse as a barrier to be circumvented, for instance, by more sophisticated methods, by liberalizing operationism, by conducting phenomenological and naturalistic inquiries, framing more complex hypotheses, utilizing computers, obtaining verbal accounts and so on (McGuire 1976). The other perspective is to view the characteristic turns in the progression of research as revealing a deeper truth about the discipline and its relation to the subject matter. More specifically, we witness a struggle in which ordinary untested knowledge plays a dual and alternating role. If we can understand this selfopposing play more thoroughly, we may be brought to a new position. To repeat an earlier point, although operationism can be analyzed logically, its stubborn persistence in the face of its heuristic weakness and its logical repudiation cannot. It has been suggested that psychologists stick to an outdated, impractical and philosophically indefensible notion of operationism because it is a talisman protecting them against the fear that psychology might not be a science after all (Leahey 1980). While this is surely close to the mark, it raises the further question whether psychologists would not feel even more secure if they kept abreast of the practices in other more developed sciences. For this reason I offer an interpretation of this methodological problem which regards it as a historical phenomenon. I shall argue that the persistence of operationism results from particular social-psychological configurations and tensions in our social existence itself. So long as these are not acknowledged and addressed in their own terms, epistemological analyses and methodological proposals are apt to fall short of the mark. The discipline can be viewed as a form of social production coming to terms with its own foundation in reality. Its knowledge is intended to accomplish something, and this intention, whether explicit or not, presupposes a specific apprehension of its subject matter, namely, the relation of the individual to social processes. Social-psychological research is not a self-contained abstract enterprise, but a motivated social activity reflecting the real relations of individuals in society.

Before making any inferences from the history of forced compliance studies to human psychology as a whole, we may wonder whether the research literature reviewed in these pages is typical. The choice of forced compliance as case study was not random. I selected it because enormous effort and ingenuity have been invested in it. Further, it is sometimes cited as a revealing example of how much objective research can accomplish in the way of reliable psychological knowledge. Thirdly, the $C D$ hypothesis was and remains an extraordinarily intriguing and insightful, if unrefined, statement about cognitive processes. Finally, it 
is a phenomenon which models a common troubling predicament of 'real life'. If this literature has failed to yield increasingly general, precise knowledge, then, I suggest, we cannot entertain much hope for literatures of lesser distinction. For these reasons, an interpretation of this case history may be useful. Still, it will be useful to refer briefly to similar problems in related fields.

Reconstructing the history of this research, one gets the impression that researchers commonly vacillated between two investigative attitudes. They took one attitude when they designed an experiment and another when they criticized it. An authoritative hypothesis (i.e., the $C D$ hypothesis) was given an empirical interpretation (i.e., forced compliance). A concrete situation was created within which a consequence of the hypothesis would be tested. Such situations necessarily incorporated features which were deemed irrelevant to the hypothesis, but which were expected to be inconsequential.

Alternating with this affirmative attitude we saw its obverse. In the sceptical attitude the researchers took the laboratory situation no longer chiefly as representing a given hypothesis, but as a meaningful and interpretable social event in its own right. Each word spoken in the laboratory and each procedural nuance were scrutinized as to the range of their likely significance to an imaginary subject. To the sceptic, the situation was not primarily an operationalization of a theory, but what it appeared to be. ${ }^{4}$

In the affirmative attitude, the investigator designs situations which he believes to be relatively univocal so that questions regarding subjects' personal definitions can be minimized or dismissed. In the sceptical attitude, these very questions are resurrected. Ambiguities which have apparently been trimmed to the irreducible minimum in the affirmative phase reclaim our attention during the sceptical phase. In both phases, informal cultural knowledge is consulted and imaginatively employed. In one phase, imagination is in the service of constructing empirical interpretations of theoretical variables with due respect to plausibility, manipulability, credibility, impact and so on. In the other phase, imagination 'borrows the eyes' of a subject and searches for likely subjective interpretations. To put this another way, in the affirmative attitude we regard the laboratory setting as a simplified model of 'real life' while in the sceptical attitude we regard it as a homogeneous and continuous segment or component of the latter.

We have seen that in the course of successive attitudinal alternations, each attempt to construct a law-like generalization was countered with an attempt to disassemble the experimental situation, regarding it not as

4 Of course, the critic too may have operated with an implicit theory of some sort, but not necessarily that which the experiment was meant to test, nor even a rival theory of attitude change. 
a milestone in experimental science, but as an isolated and selfcontained occurrence. Whereas the designers of experiments sought empirical relationships generalizable beyond the particular situations sampled, critics insisted on scrutinizing each situation within its own narrow limits. Thus, through repeated challenges to operations the attainment of generalizable, precise knowledge was blocked or retarded. But the struggle of attitudes was not one between reason and darkness, or even between behaviourists and mentalists. In each case, the two attitudes alternated in one and the same investigator. As critic, the psychologist deciphered a prior operationalization as to its unexpected significance; as experimenter, he then committed himself to new, supposedly less ambiguous operations of his own.

The train of critical reformulations impresses us with the invincible complexity of real life. Yet we do not tire of striving to master these complexities by a stroke of operationalist genius. As experimenters we are hostage to two masters: $(a)$ the empiricist's creed and $(b)$ our everyday knowledge of social life. The dispute between the affirmative and sceptical attitudes indicates that we have not fully assimilated our social experience to the metatheory of logical empiricism. We seem not quite to believe in any specific operationalization, and yet we hope to find one. Our appreciation of real-life complexities therefore occupies an uncertain, shifting position. What keeps this hapless struggle going?

Consider the practice of research as a human activity, carried on in a particular social historical setting, rather than simply as the manifestation of an abstract logic. Not only the selection of topics, but the choice of methods can be understood better when we regard social psychological research from a social-psychological perspective-as an activity carried on by individuals coming to terms with the conditions of their own and others' social existence.

What I have referred to as social or cultural knowledge, that is, knowledge which may or may not be scientifically established, which is generally shared by the members of the society and which guides our interpretation of everyday social experience despite being unsystematic and occasionally vague and self-contradictory-such knowledge is not only more voluminous than that which we succeed in establishing scientifically, but enjoys a normative privilege. Notwithstanding its 'inferior' status from a scientific perspective, it furnishes our guidelines in constructing experimental investigations and represents an implacable standard against which laboratory findings are evaluated.

Earlier I suggested a reason for this privilege. The $C D$ hypothesis and the forced compliance operation are interesting (not only to the experimenter) because they are perplexing for all of us in real life. ${ }^{5}$ Readers can

5 This may explain why the term 'cognitive dissonance' has gained currency among informed laymen. It covers our cognitive adjustments to faits accomplis. 
readily identify situations in their own lives in which they have publicly committed themselves to something they did not believe. Forced compliance represents the self-damaging effects of acquiescence to social pressure, specifically the erosion of authenticity. The cognitive, affective and social consequences of insincere commitments are troubling and neither wholly transparent nor easily avoided. This gives rise to perplexity and to a search for relief. ${ }^{6}$ The learned members of society who happen to dispose of the scholarly skills required for the clarification and resolution of perplexities accept the mission. They are familiar with this perplexity (since they are not personally exempt from its ill effects).

Given this urgent task, the stakes in finding an adequate means of studying the problem in the laboratory are higher and different from those in solving problems in the natural sciences. In regard to socialized perplexities, success has a reflexive benefit in which the experimenter himself shares. It is not necessary that he be in acute turmoil in order to recognize this. In the natural sciences, by contrast, the growth of technique and theory requires complex mediations before one's own life is materially enhanced. ${ }^{\top}$ We persist in the operationalist strategy because we hope to compress and subdue within the confines of the laboratory what plagues us uncontrollably and inescapably outside ${ }^{8}$ We expect to gain the upper hand over forces which ordinarily have us in their grip. ${ }^{9}$ Social and individual psychology therefore differ from other sciences not only cognitively, but 'motivationally'-by the nature of the stakes. The striving for mastery over human perplexity, as defined earlier, sets the social psychologist's efforts apart from the physicist's or biologist's. ${ }^{10}$

We judge laboratory investigations of perplexing phenomena by the leverage they give us on 'real life'. A satisfactory operation, one that does not suffer from excessive ambiguities, would promise us at least symbolic and eventually practical control over the sprawling problems of life. The controlling image is that of a representative sample. We posit

6 Because perplexities are socialized, they are hedged in with stabilizing rationalizations and widely taken as natural notwithstanding the malaise which they contain.

7 The contrast is attenuated in the case of a biochemist hastening to develop remedies for an illness by which he is himself imminently threatened.

8 This is rather well illustrated by the hopeful statement of a renowned social scientist who felt staggered by the complexities attending the study of "whole communities and nations'. He wrote: 'It is just possible we can manage ... the small group. The group may be small enough to let us get all the way around it' (Homans 1950, p. 3).

9 Students of archaic thought will not fail to note the element of magical thought inherent in the search for means of powerful remote influence.

10 It is not uncommon that novice experimenters display an extrascientific enthusiasm as they design ways to manipulate Anxiety, Aggression or Self-Esteem in fellow human beings. Similarly, one can hear seasoned experimenters praise research designs as exciting, cute and even sexy. 
a schematic, purified and therefore concentrated miniature of reality. The small-scale operational efficacy we hope to perfect in the laboratory can later be applied, at the desired level of magnitude, to the unmanageable world around us. We have begun to see why such leverage is not achievable.

A perplexing phenomenon is a continual irritant. Everyday forced compliance threatens one's sense of identity and obstructs one's development. That is why it commands our attention. Again and again we puzzle over it. We are familiar with its outlines but we do not penetrate to the nucleus. We have gone as far as we could but the most recalcitrant confusions remain. Thus, only the most illuminating findings will satisfy us now by helping us rise to a higher level of understanding than we had attained prior to the laboratory investigation. But such findings are difficult to obtain. ${ }^{11}$ Lesser ones we dismiss as shallow or misconceived-as though a tourist tried to convey something new to us with his cursory observations about a country or culture which we know intimately from long study and acquaintance.

In brief, because we wish urgently to gain mastery over pressing human perplexity, we are untiring in the pursuit of adequate operationalizations, and because we are relatively sophisticated about these perplexities, we tend to reject most of the attempted solutions as inadequate. Coordinate with these alternately affirmative and sceptical tendencies are the two regards in which we hold reality. In the affirmative phase we view it as containable and adequately represented by our newly contrived operations. In the sceptical phase we see this world as having yielded only in small measure, as having been only seemingly, not really, mastered. And the cycle is renewed; the struggle continues.

This dialectic explanation in terms of perplexity and mastery is intended to be social-psychological. Methodological strategies are deeply anchored in the history of thought and cannot be reduced to individual motivations. Such strategies are no more 'invented' by the individual psychologist than are each person's experiences of perplexity. Operationalist strategy continues to be zestfully pursued despite its evident difficulties because of what it means, because it portends an answer to urgent distresses prevalent in society. The relevance of a methodological strategy to such existential concerns in no way diminishes the fact that this strategy is urged upon researchers by imperatives within the discipline (graduate education, editorial policies, peer judgements, etc.). Meanings are, after all, never independent of social practices.

Yet this explanation seems too broad. Other psychological disciplines were not detained in comparable measure by the prescientific knowl-

11 For a more thorough discussion of this point, see Winch (1958) and especially Bergmann (1976). 
edge of such processes which critics brought to bear on laboratory findings. For instance, the question whether Hullian theory was adequate to the mastery of pedagogical problems in our schools was not a major deterrent to the refinement of that theory. Why should our sophistication about perplexing realities outside the laboratory foil our operationalist strategies in the laboratory? The question is pertinent because in the traditional view, the laboratory offers the advantages of controlled variation. It is assumed that the overwhelming complexity of naturally occurring phenomena can be reduced to manageable proportions. Stimuli can be manipulated singly or in combination, and distractions can be held at a minimum. Accordingly, our perplexity and our sophistication about real-life phenomena should not pose major difficulties in laboratory investigations. But this view is defective. Our case history shows that it needs qualifications.

\section{TWO REALITIES OR ONE?}

In the traditional view, life settings and laboratory settings are regarded as two distinct and independent realms. The same laws govern the events and processes taking place in each. Yet it is thought possible to arrange conditions in the laboratory which are as discontinuous from those outside as is necessary for a particular investigation. Aronson and Carlsmith distinguish two kinds of realism. They speak of experimental realism when a laboratory procedure has an impact on subjects, involves them and forces them to take it seriously. They speak of mundane realism when the events in the laboratory are judged as likely to occur in the real world (Aronson and Carlsmith 1968). According to these authors, an operation can have an impact even though it is not representative of reality. For instance, the Asch situation, which makes subjects 'squirm, sweat, and exhibit other signs of tension and anxiety', is said to be mundanely unrealistic; after all, "it is rare to find oneself in a situation where the direct and unambiguous evidence of one's senses is contradicted by the unanimous judgements of one's peers' (Aronson and Carlsmith 1968, p. 22). Milgram's situation is offered as another case of high-experimental, low-mundane realism.

This is implausible except in the most literal sense. Granted, we do not commonly administer excruciating shocks to poor learners, as Milgram's subjects thought they did. But this admission leaves us wondering from where such laboratory operations derive their indisputable impact. Is it inherent in the situation? If a complex social event (in the laboratory or elsewhere) has an impact, it cannot be totally separate from the rest of the subject's life experience. It must tap a stock of life experience-in the case of the Asch situation-with pressures toward conformity. (If it did not, the experimental findings would be uninteresting.) The same may be said about mundane pressures toward com- 
pliance which constitute the meaning and impact of the Milgram situation.

Not only are laboratory situations and real-life situations components of the same encompassing reality, but it is impossible to keep significations acquired in ordinary life experience from entering the laboratory situation. This, after all, is the gist of most of the reinterpretations of laboratory studies we reviewed earlier. The critics held that subjects brought unwanted (theoretically problematic) interpretations into the laboratory which were derived from their stock of general social knowledge. To put it another way, the objection occasionally heard from critics of laboratory research, that experimental operations are meaningless because they are contrived and artificial, is quite unfounded. On the contrary, these operations are uncontrollably meaningful because they cannot be insulated against our mundane understandings.

Of course, this meaningfulness depends on the domain of study and on the response measures employed. There are great variations in the degree of simplification and control which laboratory investigations can achieve in comparison with the real-life phenomena to which they pertain. Undoubtedly, it is easier to take segmental functions, like verbal learning, sensation or psychophysical judgement, out of their contexts than functions which involve subjectively meaningful action, which mobilize desires, fears or ideals to a significant extent, and in which subjects consequently produce themselves as persons. ${ }^{12}$

In fact, meanings of this sort are always presupposed by the experimenter, never created de novo in the laboratory. Why else would we ever recruit naive subjects or give them deceptive instructions for our operations? These instructions caption a series of tasks by placing them in a context which, though spurious, is comprehensible to the subject in terms of his or her social knowledge constituted outside the laboratory. One can imagine that not only the degree of impact, but the results of a new forced compliance study, would be dramatically altered if subjects were previously acquainted with $C D$ theory. Evidently, an experimental procedure acquires impact because it signifies one thing rather than another, and significations always depend on pre-existent categories of social experience. To speak of impact as if it were inherent foreshortens the perspective. It deals only with activation, not with meaning. Most operations in the social-psychological laboratory have impact because of what they mean. This dissolves 'the apparent paradox that experimental realism can be achieved through falsehood' (Aronson and Carlsmith 1968, p. 26).

12 Whether an experimental situation reduces real-life complexity is, therefore, not a function of tasks as such, but of tasks in settings. For instance, what perceptual judgments mean to the subject under opposing peer pressure sets the Asch situation apart from more ordinary psychophysical investigations. 
The intricate stagings familiar from forced compliance or conformity research are intended to create credible deceptions. Credibility, like comprehensibility, requires the application of pre-established significations. The mundane world is, therefore, indispensable to the laboratory. The conditions within the latter would crumble into senselessness without the semiotic support of the former.

As we have seen, this semiotic continuity has two ironic consequences: (a) Unwanted interpretations may be placed on the experimental situation, and $(b)$ since subjects do not have identical inventories of mundane experience on which to draw, their interpretations of the operations will differ among themselves in unknown ways. For this reason, Rosenberg's and the other criticisms are necessarily overextended. Some subjects may indeed have thought Cohen was bribing them, but we have no grounds for supposing that they all did! While this is surely not a new psychological insight in principle, the practice of operationism declines-again in principle!-to take account of it; a single wanted meaning is imputed to all subjects. The distinction between experimental and mundane realism is untenable.

This observation - that the laboratory situation is defined by and inseparable from the significations rooted in our 'real life' experiencetells us something positive about the nature of meanings and should not be taken primarily as a verdict against operationism. What it tells us concerns not only operationism, but any approach to the human sciences based on the 'leverage' notion. This is the notion that we can create a small-scale relatively simple replica insulated against the jumbled world around us and that this world can be kept at bay until we have perfected the means to order and subdue it. It is this notion which is faulty. Social reality defies the seclusion of the laboratory, infiltrates its significations into the supposedly protected zone and thereby contaminates and undermines the efforts at control. What happens in the laboratory is as complex and as ambiguous as what happens outside. Undergraduates obliging a kindly psychologist by telling lies to a fellow student probably put as many unregulated, divergent interpretations on the events as do job applicants in an employment interview or guests at a bridal shower.

The leverage notion is evidently more appropriate in fields of study where meanings do not figure so prominently as in social psychology. Natural scientists can create artificial self-enclosed worlds because they deal with external, physical facts and processes. When we study human subjects who interpret events, such segregations are not possible. To admit a human subject into the laboratory is to admit at the same time the meaning structures he carries in his 'real life'. We may attempt to influence, but we cannot exclude, his interpretations of laboratory events, and we cannot stop him or her from once again interpreting the 
arrangements themselves with which we attempt to influence the interpretations. Our literature review makes this plain.

Social perplexities are especially subject to this limitation for two reasons. One, as previously discussed, they revolve predominantly around confused or obstructed meanings. A perplexing predicament causes dissatisfaction in that we sense a meaning which eludes us. (We do not feel perplexed by earthquakes or toothaches.) Two, perplexities are inseparable from the totality of our life world. The sentiments and beliefs which block us from penetrating one set of perplexing phenomena, say, our own fears or vanities, play an important part in other, even unproblematic contexts of our lives, say, our excellence at work or our personal charm. What cannot be partitioned in 'real life' because of ramifying and reticulated significations cannot be sequestered in the laboratory either.

The interpreted arrangements in the laboratory will be homogeneous and continuous with, that is, of the same order as, 'real life' rather than simplified representations of it. There is no Archimedean platform from which we can lift the social world out of its hinges. This is a discouraging insight, and the more we chafe under our perplexities the more we resist it.

In our search for an effective lever, we insist on experimental operations which preserve the essential complexity and impact of the real-life equivalent. Investigators engineer highly complex situations. Not only are tasks and instructions presented to subjects so as to mislead them but, more importantly, the actual interactions among the participants (subjects, experimenters, confederates, audience) invite unregulated personal definitions. People are coaxed into making disingenuous commitments and declarations, undergoing demeaning ordeals, doing and accepting favours and so forth. Novelists thrive on the highly personalized interpretations people are wont to put on such experiences.

There are also objective ambiguities, however. For example, Aronson and Mills (1959) asked college girls to read a list of obscene words to a male experimenter, intending this exercise to be an embarrassing initiation rite. Critics pointed out that it could equally well have been an arousing experience and that either reaction would account for the obtained findings even though only the former would be relevant to $C D$ theory (Chapanis and Chapanis 1964). This ambiguity is not accidental; arousal and embarrassment are 'naturally' correlated. Earlier we saw that money can serve as a reward because subjects are already familiar with its value. But that same prior familiarity has also given rise to expectations regarding the fairness and credibility of specific remunerations. Thus, money 'naturally' combines the reward function, which the experimenter intends, with a credibility factor, which may act as a contaminant. The search for the perfect lever dooms our prospects for 
determinacy. The lever must fit the object of mastery but as it comes to resemble it too closely, it breaks under its own weight.

To speak of 'natural correlation' and of 'infiltrating meanings' is to specify a particular kind of relatedness. A contrast will make this clear. In another context, Bronfenbrenner has proposed an approach to ecological validity in which organismic development will be studied as a function of the 'interdependent, nested systems' in which it occurs (Bronfenbrenner 1977, p. 517). He advocates sensitivity to the reciprocal influences among persons and between persons and settings, higher-order effects, indirect impacts and systemic relations. His proposals rest on a biological ('ecological') metaphor and presuppose a causal model. He believes it possible to control extraneous influences, that is, to limit one's study to certain sets of subsystems and to expand these sets at will. This is roughly comparable to the astronomer's approach. One can roughly plot a planet's orbit around the sun by limiting one's calculations to the model of a two-body problem. However, for greater precision it is necessary to take into account the positions of all the other planets in the solar system. This constellative model is one of external relatedness.

By contrast, when we speak of meanings, a notion of internal relatedness seems more relevant. If a child's behaviour within different settings (family, school, peer group) is determined by the meanings they hold for $\mathrm{him} / \mathrm{her}$, then we must respect the fact that these meanings are reciprocally constitutive. The meaning of a child's peer group is apt to be related to that of school and family, for instance, as a rallying point for collective opposition or moral autonomy. Similarly, what school means is related to parental values and expectations. The child's concept of the remoter context is therefore internal to that of the present context and cannot be ousted from it. It makes no sense, however, to say that the concepts of the planets are in this sense internal to one another.

Social scientists committed to experimental study sometimes plead that these are special complex cases and that they must wait upon the formulation of simpler regularities. But this differentiation into simple and complex (or 'higher-order') effects is itself an artifact of the prevalent natural-scientific approach. The present thesis is that in the study of distinctively human phenomena-phenomena involving language-the semiotic irradiation alluded to above cannot be experimentally partitioned into elements. If it could, the findings in the laboratory would no longer bear on life.

The problematic alternation and opposition between affirmative and sceptical attitudes can be seen in this light as hinging on the investigator's shifting allegiance to analyses in terms of causes and meanings. Respect for the efficacy of the latter creates intolerance for simplifications and standardizations whereas adherence to a causal model leads to 
acquiescence in prearranged limits of error. Vacillation between models results in an endless debate about personal definitions.

The inclusion of meanings in a comprehensive theory of human actior is a methodological issue not only in operationist practice. As is wel known, Alfred Schutz explored this question in considerable detail, hi: conclusion being that the sociologist must begin with a description of the actor's social world in his or her own terms before that description car be incorporated into an account which fits the sociologist's interests anc categories (1954). Similar problems of objectivism are encountered ir content analysis, where intentions tend to be ignored (Berelson 1952 and in historical research, where events and documents are often taket out of the context of opinion and belief which endows them with signifi cance (Gottschalk 1947).

The issues here under discussion are taken up in contemporar! sociology under the heading of micro- versus macro-research (Knorr Cetina and Cicourel 1981). When investigating phenomena on one level sociologists commonly employ methods which occlude processes oc curring on the other even though the latter may be intimately, eve1 constitutively, related to the former. For example, the processes $b$ : which physicians gather medical histories from their patients are com plex and variable social interactions differing as to interrogatory style meticulousness, implicit and explicit preconceptions and so forth. $\mathrm{Bu}$ none of this is retrievable from the completed document, let alone fron aggregated public health statistics. The converse occlusion is equall: common. Micro-researchers interested in the conversational rules ob taining in small groups frequently ignore the social-structural position of the conversationalists outside the group and the role which suc micro-interactions play in maintaining macro-structural feature (Cicourel 1964, 1981). At least one theory of society holds that th impetus for social development comes from the evolving learning poter tial and competence of the society's socialized members (Haberma 1981). Thus, the occlusions of the micro-level and of micro-macro in teractions have a political as well as epistemic significance Operationism undoubtedly contributes to this larger impasse b foreshortening our perspective on subjective processes.

These prevalent paradoxical dynamics of social research can $b$ viewed in concentrated form in the social psychology laboratory. I hav argued that perplexing phenomena command our attention and energ because they gravely complicate our lives. Gaining leverage over ther is a powerful inducement to their scientific study. To this end we creat social situations in the laboratory which turn out to be quite as comple as those outside. We can perhaps control the arrangements, but neve the interpretations which subjects (and readers) place on them. Th resulting objective and subjective ambiguities are rarely resolved an 
thwart our search for the magic lever-at least in regard to perplexing phenomena. Prescientific knowledge impedes us even as it stimulates and guides us. If this is so, then, ironically, scientific progress may encounter the fewest such obstacles in domains in which we have no 'headstart' of sophistication because they hold no real-life interest for us. By contrast, we may expect that whenever we bring a phenomenon into the laboratory which is perplexing in real life, the same mundane relevance which acts as an incentive to our inquiry will also defeat us.

Finally, we consider once more the mesmeric belief that the laboratory can be isolated from 'real life' and that we can develop instruments and insights within it which will later find application in our perplexing social world. Is this not a belief growing out of the distinction between an inner, symbolic (and innocent) world and an outer, real (and problematic) one, out of the opposition of a rational mind and a scourged, impure body? Surely the problem runs deeper than method. The discipline of social psychology has placed itself in a bind by adhering to this dualism from which the polishing of methods and research designs cannot free us. That is why it would be self-contradictory and hasty to propose superior approaches at this point. New methods can in time be developed out of a non-dualistic reconceptualization of socialpsychological research, that is, after the relinquishment of the leverage illusion. An interpretive discipline seems most promising (Taylor 1979). I shall show elsewhere what this means in practice (Rosenwald 1985).

The scientific strategy currently being pursued suffers from the same problems as the social world it seeks to study. Operationism reflects as well as perpetuates a socially created, not an ontological, duality-the sundering of the individual (investigator) into social atom and irrepressible subject. As the former, he makes compromises for Science; as the latter he knows better and protests. To address this enforced duality requires that the search for knowledge become identical with its application, that research become a factor in resocialization. Seemingly, nothing short of a revision of the self-concept of the social sciences will do. Having traced the sources of the current strategy to the social order, we can understand better why methodological exhortations do not work. At the same time, this intransigence reveals the sheer power of perplexing socialization: to cut through the Gordian knot, we have set our hopes and tightened our grip on one of the dullest blades available.

\section{REFERENCES}

Allport, G. W. (1961) Pattern and Growth in Personality. New York.

Aronson, E. (1966) 'The Psychology of Insufficient Justification', in S. Feldman (ed.), Cognitive Consistency. New York.

(1969) 'The Theory of Cognitive Dissonance: A Current Perspective', in L. Berkowitz (ed.), Adrances in Experimental Social Psychology, vol. 4. New York. 
Aronson, E. and Carlsmith, J. M. (1968) 'Experimentation in Social Psychology', in G. Lindzey and E. Aronson (eds.), The Handbook of Social Psychology, 2nd ed., vol. 2. Reading, Mass.

Aronson, E. and Mills, J. (1959) 'The Effect of Severity of Initiation on Liking for a Group', Journal of Abnormal and Social Psychology, 59, 177-81.

Berelson, B. (1952) Content Analysis in Communication Research. New York.

Bergmann, F. (1976) 'Epistemology and Social Science', unpublished monograph, University of Michigan.

Brehm, J. W. (1965) "Comment on "Counter-norm Attitudes Induced by Consonant Versus Dissonant Conditions of Role-playing", , Journal of Experimental Research in Personality, 1, 61-64.

Brehm, J. W. and Cohen, A. R. (1962) Explorations in Cognitive Dissonance. New York.

Bridgman, P. W. (1927) The Logic of Modern Physics. New York.

Bronfenbrenner, U. (1977) 'Toward an Experimental Ecology of Human Development', American Psychologist, 32, 513-31.

Carlsmith, J. M., Collins, B. E. and Helmreich, R. C. (1966) 'Studies in Forced Compliance: 1 . The Effect of Pressure for Compliance on Attitude Change Produced by Face-to-face Role Playing and Anonymous Essay Writing', Journal of Personality and Social Psychology, 4, 1-13.

Chapanis, N. and Chapanis, A. (1964) 'Cognitive Dissonance: Five Years Later', Psychological Bulletin, 61, 1-22.

Cicourel, A. V. (1964) Method and Measurement in Sociology. New York. (1981) 'Notes on the Integration of Micro- and Macro-levels of Analysis', in K. Knorr-Cetina and A. V. Cicourel (eds.), Adrances in Social Theory and Methodology. Boston.

Cohen, A. R. (1962) 'An Experiment on Small Rewards for Discrepant Compliance and Attitude Change', in J. W. Brehm and A. R. Cohen (eds.), Explorations in Cognitive Dissonance. New York.

Collins, B. E. (1969) 'The Effect of Monetary Inducements on the Amount of Attitude Change Produced by Forced Compliance', in A. C. Elms (ed.), Role-playing, Reward, and Attitude Change. New York.

Cook, T. D. and Campbell, D. T. (1979) Quasi-experimentation: Design and Analysis Issues for Field Settings. Chicago.

Duhem, P. (1962) The Aim and Structure of Plyysical Theory. New York.

Eagly, A. and Himmelfarb, S. (1978) 'Attitudes and Opinions', Annual Review' of Psychology, 29, 517-54.

Earnest, W. R. (1982) 'Work and Its Discontent', unpublished doctoral dissertation, University of Michigan.

Fazio, R. H., Zanna, M. P. and Cooper, J. (1977) 'Dissonance and Self-perception: An Integrative View of Each Theory's Proper Domain of Application', Journal of Experimental Social Psychology, 13, 464-79.

Festinger, L. (1957) A Theory of Cognitive Dissonance. Stanford, Calif.

Festinger, L. and Carlsmith, J. (1959) 'Cognitive Consequences of Forced Compliance', Journal of Abnormal and Social Psychology, 58, 203-10.

Gergen, K. J. (1982) Toward Transformation in Social Knowledge. New York.

Giorgi, A. (1970) Psychology as a Human Science. New York.

Gottschalk, L. (1947) 'The Historian and the Historical Document', in L. Gottschalk, C. Kluckhohn and R. Angell (eds.), The Use of Personal Documents in History, Anthropology, and Sociology. New York.

Greenwald, A. G. (1975) 'On the Inconclusiveness of "Crucial" Cognitive Tests of Dissonance Versus Self-perception Theories', Journal of Exerimental Social Psychology, 11, 490-99.

Greenwald, A. G. and Ronis, D. L. (1981) 'On the Conceptual Disconfirmation of Theories', Personality and Social Psychology Bulletin, 7, 131-37. 
Habermas, J. (1981) 'Toward a Reconstruction of Historical Materialism', in K. KnorrCetina and A. V. Cicourel (eds.), Advances in Social Theory and Methodology. Boston.

Hanson, N. R. (1971) 'The Idea of a Logic of Discovery', in S. Toulmin and H. Woolf (eds.), What I Do Not Believe and Other Essays. New York. (1973) 'Observation', in R. E. Grandy (ed.), Theories and Observation in Science. Englewood Cliffs, N.J.

Harré, R. and Secord, P. F. (1972) The Explanation of Social Behavior. Totowa, N.J.

Hempel, C. G. (1966) Philosophy of Natural Science. Englewood Cliffs, N.J.

Homans, G. C. (1950) The Human Group. New York.

Janis, I. L. and Gilmore, J. B. (1965) 'The Influence of Incentive Conditions on the Success of Role-playing in Modifying Attitudes', Journal of Personality and Social Psychology, 1, 17-27.

Katz, I. (1967) 'Editorial', Journal of Personality and Social Psychology, 7, 341-44.

Knorr-Cetina, K. and Cicourel, A. V. (1981) Advances in Social Theory and Methodology: Toward an Integration of Micro- and Macro-sociologies. Boston.

Kuhn, T. J. (1962) The Structure of Scientific Revolutions. Chicago.

Leahey, T. H. (1980) 'The Myth of Operationism', Journal of Mind and Behavior, 1, 127-43.

McGuire, W. J. (1976) 'The Yin and Yang of Progress in Social Psychology', in L. H. Strickland, F. E. Aboud and K. J. Gergen (eds.), Social Psychology in Transition . New York.

Meehl, P. E. (1978) 'Theoretical Risks and Tabular Asterisks: Sir Karl, Sir Ronald, and the Slow Progress of Soft Psychology', Journal of Consulting and Clinical Psychology, 46, 806-34.

Natsoulas, T. (1978) 'Residual Subjectivity', American Psychologist, 33, 219-83.

Nuttin, J. M., Jr. (1964) 'Dissonant Evidence About Dissonance Theory', paper read at Second Conference of Experimental Social Psychologists in Europe, Frascati, Italy.

Popper, K. (1959) The Logic of Scientific Discovery. New York.

Quine, W. V. (1961) 'Two Dogmas of Empiricism', in W. V. Quine (ed.), From a Logical Point of View. Cambridge, pp. 20-46.

Quine, W. V. and Ullian, J. S. (1970) The Web of Belief. New York.

Reichenbach, H. (1938) Experience and Prediction. Chicago.

Rosenberg, M. J. (1965) 'When Dissonance Fails', Journal of Personality and Social Psychology, 1, 28-42.

Rosenwald, G. C. (1985) 'Hypocrisy, Self-deception, and Perplexity: The Subject's Enhancement as Methodological Criterion', Journal of Personality and Social Psychology, 49, 682-703.

Schutz, A. (1954) 'Concept and Theory Formation in the Social Sciences', Journal of Philosophy, 51, 257-73.

Scriven, M. (1964) 'Comments of Professor Scriven', in T. W. Wann (ed.), Behaviorism and Phenomenology. Chicago.

Sears, D. O. and Abeles, R. P. (1969) 'Attitudes and Opinions', Annual Review of Psychology, 20, 253-88.

Sennett, R. D. and Cobb, J. (1973) The Hidden Injuries of Class. New York.

Silverman, I. (1977) 'Why Social Psychology Fails', Canadian Psychological Review, 18, 353-58.

Suppe, F. (1977) The Structure of Scientific Theories. Urbana, Ill.

Taylor, C. (1979) 'Interpretation and the Sciences of Man', in P. Rubinow and W. M. Sullivan (eds.), Interpretive Social Science: A Reader. Berkeley.

Wicklund, R. A. and Brehm, J. W. (1976) Perspectives on Cognitive Dissonance. Hillsdale, N.J.

Winch, P. (1958) The Idea of a Social Science and Its Relation to Philosophy. London. 